\title{
Measurement of Dielectric Constant \& Loss Factor for Three States of Grains Using Microwave Frequency (CJ-Band and X-band)
}

\author{
Akhil Kumar Jain \\ ${ }^{1}$ Institute of Engineering \& Technology Alwar, \\ North Extension M.I.A. Alwar - 301030 (Rajasthan), India
}

\begin{abstract}
The paper speaks to the investigation of dielectric constants alongside their loss factor for different sorts of grains which characterize their reactions against electromagnetic energy at various microwave frequencies by absorbing, radiates, reflect, and disperse a segment of electromagnetic energy. Estimation of dielectric consistent and loss factor have made for different specimens of grains, for example, Rice, Wheat, Split Red Gram (Arhar), Bengal Gram (Chana), Green Gram (Moong) for three unique states as preliminary, oven dried and saturated at various gravimetric moisture content in scope of CJ Band at two different frequency values $(5.30$ and $6.60 \mathrm{GHz}$ ) and furthermore in the scope of $X$ Band at frequency of $10.65 \mathrm{GHz}$ by utilizing waveguide cell (short-circuited lines or double minima or two point) technique. The general lab measurements are similarly critical in recognizing the grains and relatively increase the characterized crop productivity by using microwave remote sensing applications. The analytical study of various grains and pulses at microwave frequencies may give data about the vegetation field and furthermore distinguishes their behavioral properties.
\end{abstract}

Keywords: Dielectric constant, Gravimetric moisture content, Waveguide cell, Preliminary, Oven dried, saturated, Microwave remote sensing, CJ Band, X Band, vegetation

\section{Introduction}

Dielectric properties are, by definition, a measure of the polarizability of a material when subjected to an electric field. [1]-[2] For lossy materials, the relative complex permittivity, $\varepsilon=\varepsilon^{\prime}-\mathrm{j} \varepsilon^{\prime \prime}$, represents the dielectric properties of materials.

Use of microwave energy for microwave dielectric heating of materials is an important application requiring information about the dielectric properties of the materials. Use of lower levels of microwave energy for measurements such as moisture content sensing is another important area for which dielectric properties information about the materials is essential. [3]

The dielectric constant, $\varepsilon$ ', describes the material's ability to store energy (electromagnetic energy), the dielectric loss factor $\varepsilon$ ", describes the material's ability to dissipate the electric field energy, and $\mathrm{j}$ is the imaginary root of -1 . [4]

The dielectric properties of many materials depend on frequency, moisture content, bulk density, temperature, chemical composition, and the permanent dipole moments association with water and other constituent molecules.[5][10]. The loss factor is related to the capability of the material for absorbing energy from the electric field. [6]

The dielectric properties of agricultural or biological materials have much significance in processing of agricultural commodities and food. Concept and idea regarding the dielectric properties of agricultural commodities enables us to understand the interactions between electromagnetic wave and vegetation, in order to inspire the development of RF treatments for agricultural products. [11]-[12]
In granular and particulate materials like cereals and grains, the bulk density of the air-particle mixture is another factor that influences the permittivity. [13]

Therefore, a significant need exists for analytical expressions describing the dielectric properties of different kinds of grain at particular frequencies as functions of density and moisture content. [14]

This attenuation is due to scattering and absorption of the transmitted wave as it propagates through areas of vegetation. [15]

Generally, both the dielectric constant and loss factor show monotonic decreases in value as frequency increases.

Temperature and moisture content cause variations in the value of dielectric constant for different frequencies. At lower frequencies the dielectric constant (conductivity) increases with the temperature but it is not as so for higher frequencies, whereas for loss factor, it is more different with the temperature.

Researchers have tested different techniques of using the dielectric properties of biomaterials to estimate water content present in the cereal. These studies include transmission line techniques such as waveguide (coaxial and free-space), impedance and cavity methods. [16]

\section{Measurement of Dielectric Constant}

When microwaves are applied to any material, one part of the energy is reflected, part is transmitted through the surface of the granular elements of the material, and part of it is absorbed by it. The fundamental electrical property through 


\section{International Journal of Science and Research (IJSR) \\ ISSN (Online): 2319-7064}

Index Copernicus Value (2015): 78.96 Impact Factor (2015): 6.391

which the interactions are described is the complex relative permittivity of the material. [17]

Dielectric constant for the lossy medium can be formulated as:

$$
\varepsilon_{y}=\varepsilon^{v}{ }_{y}+\frac{(\sigma)}{\left(j \omega \varepsilon_{0}\right)}
$$

Here,

$\sigma=\omega \varepsilon_{0} \varepsilon^{\prime \prime}$ Dielectric conductivity in Siemens per meter (sums overall dissipative effects of the grains)

$\varepsilon^{\prime} \mathrm{r}=$ real valued permittivity $=$ Dielectric Storage Factor

$\omega=2 \pi \mathrm{c} / \lambda=2 \pi \mathrm{f}=$ angular frequency $(\mathrm{f}$ in $\mathrm{Hz}$ )

$\varepsilon_{0}=1 /\left(\mu_{0} \mathrm{c}^{2}\right)=8.854 \times 10-12 \mathrm{~F} / \mathrm{M}$ permittivity of free space reduces to:

$$
\varepsilon_{y}=\varepsilon^{s}-j \sigma \lambda \kappa
$$

Here,

$\kappa=\mu_{0} \mathrm{c} / 2 \pi$

$\mathrm{j}=\sqrt{ }-1$

$\sigma \lambda \kappa=\varepsilon_{r}^{\prime \prime}=$ Dielectric Loss Factor

So,

$$
\varepsilon_{r}=\varepsilon^{\prime}{ }_{r}-j \varepsilon^{\prime \prime}{ }_{r}=\left|\varepsilon^{\prime}\right| e-j \delta
$$

$\delta$ - Loss angle of dielectric i.e. $\tan \delta=\varepsilon^{\prime \prime} / \varepsilon^{\prime}$ is the tangent loss or dissipative factor.

$\mathrm{r}$ - The subscript used for simplification in the remainder of this article. [18]

The real part of the permittivity represents the energy storage capability in the electric field in the dielectric material, and the imaginary part represents the energy dissipation capacity of the dielectric by which energy from the electric field is converted into heat energy in the dielectric. [19]

In RF treatments, electromagnetic energy interacts directly with commodities containing polar molecules and charged ions to generate heat. The way in which any material interacts with electromagnetic energy may be described by their dielectric properties. Dielectric properties have been reported for different frequency ranges.

\section{Sample Grains: Cereals and Pulses}

\subsection{Wheat}

The grain of any cereal grass of the genus Triticum, especially T. aestivam, with moist dry weather condition, grown in clay and loamy soil used for culinary and nutritional purposes.

\subsection{Rice}

A cereal grass (Oryza sativa) that is cultivated extensively in warm climates in the areas having heavy rainfall for its edible grain.

\subsection{Green Gram}

A well-known as Moong is a Kharif crop grown in moistened summer season.

\subsection{Split Red Gram}

It is grown in summer season cultivated during warm tropical and subtropical climate, requires fertile soil.

\subsection{Bengal Gram}

It requires irrigation, and grown in less heavy soil texture having drain and rainy conditions in winter season.

\section{Materials and Methods}

\subsection{Sample Preparation}

1) Preliminary sample

2) Oven dried sample

3) Saturated sample

During sample preparation, same sample only, of different varieties of grains undergo from all the three different physical states (i.e. of preliminary, oven-dried, and saturated states) successively.

\subsection{Method Used}

The most widely used and versatile microwave measurement technique is the twopointm0ethod of measuring the complex dielectric constant involving the solution of a transcendental equation. The input impedance of a short circuited waveguide is measured with and without the sample and a transcendental equation is solved.

This method is very simple but may lack accuracy depending on the exact sample length.

Further for the dry and wet samples, which is nonhomogeneous medium having grain particles, air voids and water, it is difficult to arrange the sample uniformly with same density profile in the total length of the sample holder waveguide.

The two-point method is best known and most widely used for the measurement of complex permittivity. It is best suited to either "lossless" dielectrics or the dielectrics with medium loss. 

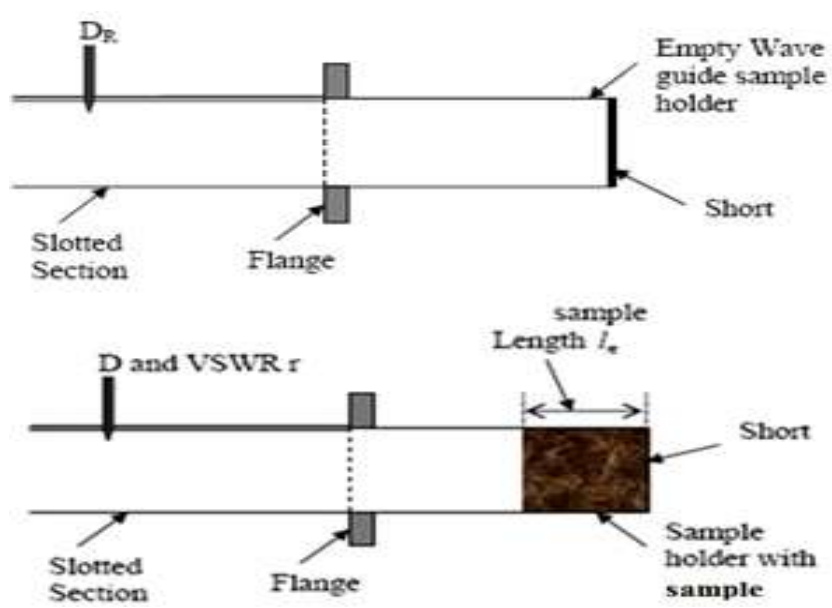

Figure 1: Two different stages of waveguide without and with sample

Figure 1 shows an empty short-circuited waveguide with a probe located at a voltage minimum and then the same waveguide, containing a sample of length $l \varepsilon$ with the probe located at a new voltage minimum Dr. The sample is adjacent to the short circuit.

It should be noted that the accuracy of the experimental results of complex permittivity using this method depends to a large extent on the smoothness of the sample, the fitting of the sample in the waveguide, the care which has been taken to insure that its surfaces are properly "squared" with respect to each other, the accuracy of measurement of length $1 \varepsilon$ of the sample, the position of minima Dr and D and the accuracy in the measurement of VSWR i.e. Voltage standing wave ratio.

The estimation of dielectric constant has been made using the measure values of dielectric constant using two point method in three microwave frequencies of CJ-band(5.30 and 6.60 $\mathrm{GHz})$ and $\mathrm{X}-\mathrm{Band}(10.65 \mathrm{GHz})$.

Since dielectric properties are also dependent on the temperature and bulk density, or test weight, of grain and seed samples, corrections must be made for deviations of either variable to avoid errors in moisture readings. For moisture content we used distilled water as its complex permittivity is known. [20]

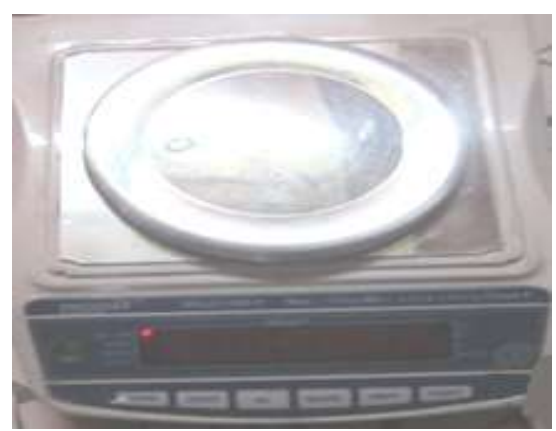

Figure 2: Calibrated sample weighing machine

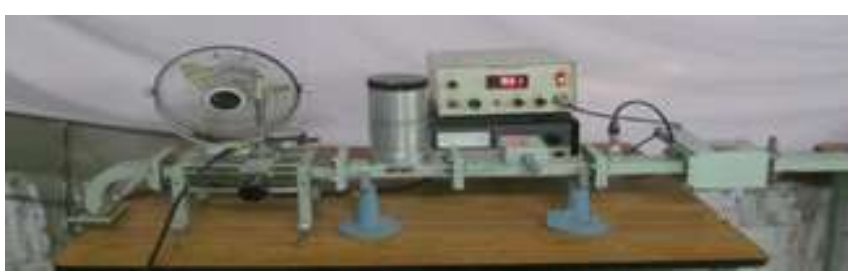

Figure 3: Set up for measurement of dielectric constant at CJ- Band (3.95-5.85 GHz)

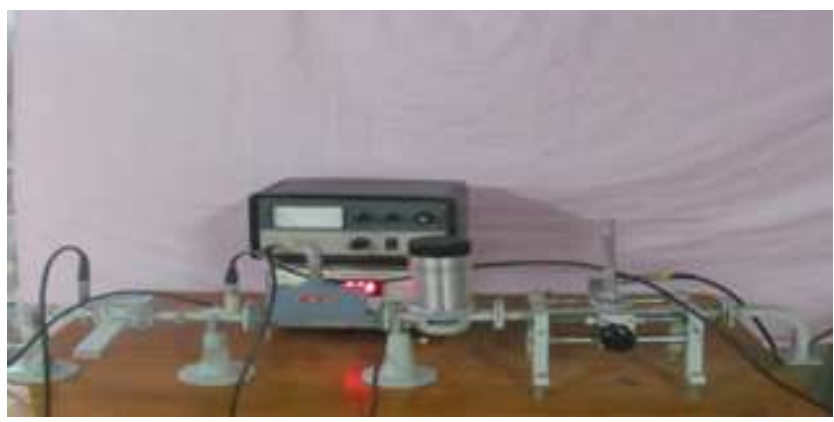

Figure 4: Set up for measurement of dielectric constant at XBand (8.20-12.4 GHz)

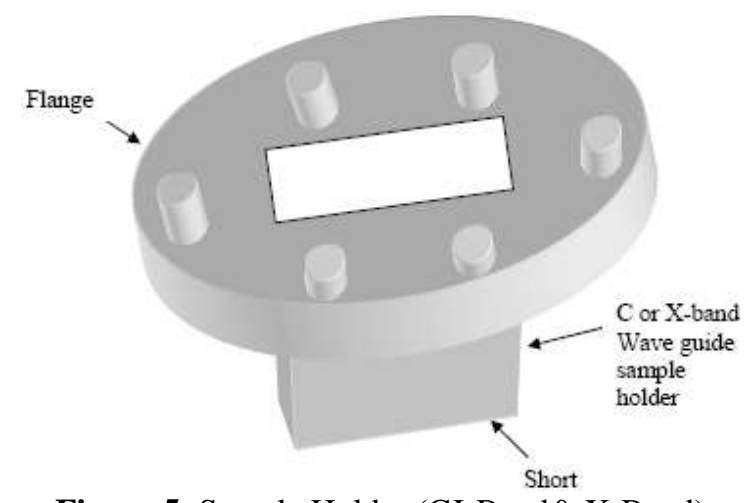

Figure 5: Sample Holder (CJ-Band\& X-Band)

The method used in measurement of dielectric constant of a solid material like cereals is based upon basic fundamentals of the microwave equipment's.

In this waveguide cell method, the dielectric constant is measured by calculating the shift in minima of the standing wave pattern in a rectangular waveguide. This shift takes place due to the change in the guide wavelength when a dielectric material is introduced in waveguide. [21]

Here, the measurement of guide wavelength is carried out at three microwave frequencies.

Table 1: Analyzed Frequency Band

\begin{tabular}{|c|c|}
\hline Band & Frequency $(\mathrm{GHz})$ \\
\hline CJ-Band & 5.3 \\
\hline CJ-Band & 6.6 \\
\hline X-Band & 10.65 \\
\hline
\end{tabular}

The relevant equations used for determining the dielectric constant in the given frequencies are as follows:-

$$
k=\frac{2 \pi}{\lambda_{g}}
$$

\section{Volume 6 Issue 9, September 2017 www.ijsr.net}


Here,

$\mathrm{k}=$ Propagation constant

$\lambda \mathrm{g}=$ Guide wavelength

$$
\begin{gathered}
\varepsilon^{H}=\left(-\mathrm{B}_{\mathrm{e}} /\left(1+\left(\lambda_{\mathrm{g}} / 2 \mathrm{a}\right) 2\right)\right) \\
\varepsilon_{y}=\varepsilon^{s}-\mathrm{j} \varepsilon^{n s}
\end{gathered}
$$

Here,

$\varepsilon^{\prime}=$ storage factor

$\varepsilon "=$ loss factor

$\varepsilon \mathrm{r}=$ dielectric constant

\section{Procedure and Precautions}

Different physical states weighed samples (i.e. Rice, Wheat, Red Split Gram, Green Gram, and Bengal Gram) for measurements are taken into the sample holder and try to make it homogenous so that no air gap is present in it.

Now, the sample holder carefully tightened with the help of nuts and screws to the slotted section of the rectangular waveguide of respective operating frequencies and makes it vertically aligned. After then apply the Gunn Power supply to Gunn oscillator and determine the two voltage minima shifts with the help of SWR meter and slotted section; determine the guided wavelength ' $\lambda \mathrm{g}$ ' and then VSWR with the help of related formulas\& equations and then determine the dielectric constant with the help of computer programs.

Some important precautions regarding the experimental setup and procedure have to keep in mind as follows:

- Weight of each sample must be read out before inserting in the sample holder or before starting the measurements for every state of sample.

- Sample holder must be dry properly to avoid the losses due to moisture content in dry or saturation state of the cereal.

- For measurement of moisture content in decreasing order we need sun illumination to reduce the moisture content of saturated sample thus the measurements should be completed in a day for respective saturated sample to get proper sunlight and to prevent from unnecessary moisture changes due to varying environmental conditions at night.

- The radiation losses are lead due to inhomogeneous surface of the sample filled in the sample holder. It should be ensured that the surface of cereal should be homogeneous as much as possible.

- Store the grain sample in the container after the measurement for each of the three states properly in order to avoid the original mass material loss of the sample.

- Due to improper procedure, lack of basic fundamentals about the microwave equipment's and components, shortcomings in proper arrangement of sample in sample holder may lead to variations in the measurements of dielectric constant \& loss factor of grains under test.

\section{Results \& Discussions}

For frequencies $5.30 \mathrm{GHz}, 6.60 \mathrm{GHz}$ and $10.65 \mathrm{GHz}$ measurements taken for different form of cereals which includes dielectric constant and loss factor (i.e. $\varepsilon^{\prime}$ and $\varepsilon^{\prime \prime}$ ) are given as follows-

$$
\varepsilon^{f}=\left(\left(G_{e}+\left(\lambda_{g} / 2 \mathrm{a}\right) 2\right) /\left(1+\left(\lambda_{\mathrm{g}} / 2 \mathrm{a}\right) 2\right)\right)
$$




\section{International Journal of Science and Research (IJSR) \\ ISSN (Online): 2319-7064}

Index Copernicus Value (2015): 78.96 | Impact Factor (2015): 6.391

Table 1: Dielectric Constant and loss factor of grains for CJBand $(5.3 \mathrm{GHz})$

\begin{tabular}{|c|c|c|}
\hline Samples & $\begin{array}{c}\text { Dielectric } \\
\text { Constant }\end{array}$ & Loss Factor \\
\hline \multicolumn{3}{|c|}{ Preliminary } \\
\hline Wheat & 9.0370 & 0.5077 \\
\hline Rice & 8.7754 & 1.0614 \\
\hline Arhar & 8.6727 & 0.0591 \\
\hline Chana & 8.4098 & 0.846 \\
\hline Moong & 8.8048 & 1.2907 \\
\hline \multicolumn{3}{|c|}{ Oven Dried } \\
\hline Wheat & 8.8458 & 0.8423 \\
\hline Rice & 8.2015 & 0.2351 \\
\hline Arhar & 8.1903 & 1.5508 \\
\hline Chana & 8.0805 & 1.6259 \\
\hline Moong & 8.4429 & 0.5021 \\
\hline \multicolumn{3}{|c|}{ Saturated } \\
\hline Wheat & 11.0423 & 3.9736 \\
\hline Rice & 11.0012 & 3.2430 \\
\hline Arhar & 10.8084 & 2.3152 \\
\hline Chana & 11.2015 & 3.5625 \\
\hline Moong & 10.7458 & 2.6927 \\
\hline
\end{tabular}

Table 2: Dielectric Constant and loss factor of grains for CJBand $(6.6 \mathrm{GHz})$

\begin{tabular}{|c|c|c|}
\hline Samples & $\begin{array}{c}\text { Dielectric } \\
\text { Constant }\end{array}$ & Loss Factor \\
\hline \multicolumn{3}{|c|}{ Preliminary } \\
\hline Wheat & 8.8451 & 0.4132 \\
\hline Rice & 8.5023 & 0.6594 \\
\hline Arhar & 8.4805 & 1.2361 \\
\hline Chana & 8.2315 & 0.1625 \\
\hline Moong & 8.5509 & 1.2365 \\
\hline \multicolumn{3}{|c|}{ Oven Dried } \\
\hline Wheat & 8.6450 & 0.1527 \\
\hline Rice & 8.0509 & 1.6718 \\
\hline Arhar & 8.0010 & 0.9827 \\
\hline Chana & 7.9998 & 1.1560 \\
\hline Moong & 8.0521 & 0.2376 \\
\hline \multicolumn{3}{|c|}{ Saturated } \\
\hline Wheat & 10.8264 & 3.7927 \\
\hline Rice & 10.7765 & 3.1592 \\
\hline Arhar & 10.2128 & 2.6051 \\
\hline Chana & 11.0519 & 3.0519 \\
\hline Moong & 10.5023 & 2.0010 \\
\hline
\end{tabular}

Table 3: Dielectric Constant and loss factor of grains for $\mathrm{X}$ Band (10.65 GHz)

\begin{tabular}{|c|c|c|}
\hline Samples & $\begin{array}{c}\text { Dielectric } \\
\text { Constant }\end{array}$ & Loss Factor \\
\hline \multicolumn{3}{|c|}{ Preliminary } \\
\hline Wheat & 6.6645 & 1.9533 \\
\hline Rice & 6.6402 & 1.9600 \\
\hline Arhar & 6.8166 & 1.9997 \\
\hline Chana & 6.4729 & 1.7403 \\
\hline Moong & 6.3555 & 1.9389 \\
\hline \multicolumn{3}{|c|}{ Oven Dried } \\
\hline Wheat & 6.2392 & 0.7156 \\
\hline Rice & 6.0010 & 0.1724 \\
\hline Arhar & 6.5158 & 0.7860 \\
\hline Chana & 6.0264 & 1.0644 \\
\hline Moong & 6.0853 & 1.1755 \\
\hline \multicolumn{2}{|c|}{ Saturated } \\
\hline Wheat & 8.5066 & 2.0152 \\
\hline
\end{tabular}

\begin{tabular}{|c|c|c|}
\hline Rice & 8.2617 & 1.9573 \\
\hline Arhar & 7.2047 & 1.6955 \\
\hline Chana & 7.8613 & 1.5868 \\
\hline Moong & 7.4480 & 1.7532 \\
\hline
\end{tabular}

\subsection{Miscellaneous research of Cereals and Pulses}

To observe the versatility in dielectric constant and loss factor with frequency, the analysis were done at different frequencies. The values of dielectric constant and loss factor are estimated for different samples in preliminary oven dried and saturated states respectively in the frequency range 5.30 $\mathrm{GHz}$ to $10.65 \mathrm{GHz}$.

It is analyzed that the dielectric constant and loss factor of five different samples are distinct by virtue of disparity in their physical properties and presence of moisture content. The data have been obtained by taking ten sets of readings for each sample and each set comprising of three values of the shift in minima obtained throughout the length of the slotted waveguide. In all, thirty readings were taken for each sample for each frequency. The process is repeated in order to check the accuracy and precision of microwave system used. The sets of readings were taken for frequency mentioned in the table and can also predict that there is slight variation in the value of dielectric constant and loss factor with the increase in frequency.

\subsection{Resultant variation in Dielectric Constant and Loss factor with different moisture content}

The variability in dielectric constant and loss factor can be attributed to the presence of moisture in the samples, which they absorb when kept exposed to the atmosphere at different microwave frequencies. It is wholly depends upon the variations in setup arrangement with accuracy and efficiency.

The loss of radiation in environment does affect the values of dielectric constant leads to the moisture content present in the sample under experiment. For different kinds of microwave energy the level of radiation loss will be differ which remain in the final values of constant and loss factor.

The dielectric constant and loss factor of the samples were measured after determining the weight of the sample before the measurement. Some measurements were also made before the settlement and just after adding water to cereals at the saturated limit of water-cereals mixture.

In the present study, the measurements were made for the preliminary samples, oven dried sample and sample having moisture content $2 \%, 5 \%, 10 \%, 20 \%, 30 \%$.The results of measurements of moisture content of $2 \%$ to $30.00 \%$ have been tabulated in this properly.

Dielectric constant and loss factor changes with humidity or water with water content, so that special arrangements have to be made to hold humidity constant and to determine its value or we can do it naturally just by drying it in air.

Grain moisture content is expressed as a percentage of moisture based on wet weight (wet basis) or dry matter (dry 


\section{International Journal of Science and Research (IJSR) ISSN (Online): 2319-7064 \\ Index Copernicus Value (2015): 78.96 | Impact Factor (2015): 6.391}

basis). Wet basis moisture content is generally used. Dry basis is used primarily in research.

$$
\begin{aligned}
& M w(\text { wet basis })=\frac{w-d}{w} *(100) \\
& \operatorname{Md}(\text { dry basis })=\frac{w-d}{d} *(100)
\end{aligned}
$$

Here,

$$
\begin{aligned}
& \mathrm{w}=\text { wet weight } \\
& \mathrm{d}=\text { dry weight } \\
& \mathrm{M}=\text { moisture content on a percent basis. }
\end{aligned}
$$

A representative sample must be obtained to provide a useful moisture content evaluation. Also, the moisture content of the product must be maintained from the time the sample is obtained until the determination is made by storing in a sealed container.

The moisture content can be determined by an oven method, which is a direct method. The grain is weighed and dried, then weighed again according to standardized procedures. The moisture content is calculated using the moisture content equations. Most moisture meters measure the electrical properties of grain, which change with the moisture content. This is considered an indirect method and must be calibrated by a direct method. It is important to follow moisture meter directions carefully to achieve an accurate moisture test. A

\begin{tabular}{|c|c|c|c|c|c|c|}
\hline \multirow{3}{*}{$\begin{array}{c}\text { Moisture Content in } \\
\%\end{array}$} & \multicolumn{6}{|c|}{ For Wheat } \\
\hline & \multicolumn{3}{|c|}{ Dielectric Constant } & \multicolumn{3}{|c|}{ Loss Factor } \\
\hline & $5.3 \mathrm{GHz}$ & $6.6 \mathrm{GHz}$ & $10.65 \mathrm{GHz}$ & $5.3 \mathrm{GHz}$ & $6.6 \mathrm{GHz}$ & $10.65 \mathrm{GHz}$ \\
\hline 30 & 11.0423 & 11.0423 & 8.5065 & 2.0152 & 2.3702 & 3.4927 \\
\hline 20 & 10.965 & 10.965 & 7.234 & 1.7851 & 1.961 & 2.9903 \\
\hline 10 & 10.126 & 10.126 & 7.940 & 1.2613 & 1.465 & 2.0321 \\
\hline 5 & 9.8620 & 9.8620 & 7.028 & 0.6933 & 0.952 & 1.8406 \\
\hline 2 & 9.0512 & 9.0512 & 6.471 & 0.2832 & 0.501 & 1.0521 \\
\hline \multirow{3}{*}{$\begin{array}{c}\text { Moisture Content in } \\
\%\end{array}$} & \multicolumn{6}{|c|}{ For Rice } \\
\hline & \multicolumn{3}{|c|}{ Dielectric Constant } & \multicolumn{3}{|c|}{ Loss Factor } \\
\hline & $5.3 \mathrm{GHz}$ & $6.6 \mathrm{GHz}$ & $10.65 \mathrm{GHz}$ & $5.3 \mathrm{GHz}$ & $6.6 \mathrm{GHz}$ & $10.65 \mathrm{GHz}$ \\
\hline 30 & 11.001 & 10.7765 & 8.261 & 1.9573 & 2.335 & 3.1593 \\
\hline 20 & 10.862 & 10.3096 & 7.511 & 1.6123 & 2.011 & 2.9621 \\
\hline 10 & 9.9737 & 9.8401 & 7.157 & 1.2305 & 1.864 & 2.1156 \\
\hline 5 & 9.1456 & 8.9872 & 6.821 & 0.9156 & 1.531 & 1.7553 \\
\hline 2 & 8.9112 & 8.8562 & 6.192 & 0.2059 & 1.288 & 1.4125 \\
\hline \multirow{3}{*}{$\begin{array}{c}\text { Moisture Content in } \\
\%\end{array}$} & \multicolumn{6}{|c|}{ For Arhar } \\
\hline & \multicolumn{3}{|c|}{ Dielectric Constant } & \multicolumn{3}{|c|}{ Loss Factor } \\
\hline & $5.3 \mathrm{GHz}$ & $6.6 \mathrm{GHz}$ & $10.65 \mathrm{GHz}$ & $5.3 \mathrm{GHz}$ & $6.6 \mathrm{GHz}$ & $10.65 \mathrm{GHz}$ \\
\hline 30 & 10.8084 & 10.2128 & 7.2047 & 1.6955 & 1.8566 & 2.3152 \\
\hline 20 & 10.210 & 10.044 & 7.0988 & 1.5103 & 1.667 & 2.0915 \\
\hline 10 & 9.8815 & 9.7513 & 6.8751 & 1.0325 & 1.121 & 1.8854 \\
\hline 5 & 9.5325 & 9.3705 & 6.4856 & 0.5213 & 0.742 & 1.4261 \\
\hline 2 & 9.0856 & 8.2975 & 6.0111 & 0.2856 & 0.301 & 1.0196 \\
\hline \multirow{3}{*}{$\begin{array}{c}\text { Moisture Content in } \\
\%\end{array}$} & \multicolumn{6}{|c|}{ For Chana } \\
\hline & \multicolumn{3}{|c|}{ Dielectric Constant } & \multicolumn{3}{|c|}{ Loss Factor } \\
\hline & $5.3 \mathrm{GHz}$ & $6.6 \mathrm{GHz}$ & $10.65 \mathrm{GHz}$ & $5.3 \mathrm{GHz}$ & $6.6 \mathrm{GHz}$ & $10.65 \mathrm{GHz}$ \\
\hline 30 & 11.201 & 11.0519 & 7.861 & 1.5868 & 2.280 & 3.0519 \\
\hline 20 & 10.552 & 10.5118 & 7.732 & 1.1961 & 2.057 & 2.6214 \\
\hline 10 & 9.9880 & 9.9625 & 7.221 & 0.8923 & 1.815 & 2.1392 \\
\hline 5 & 9.5119 & 9.4492 & 6.831 & 0.8462 & 1.307 & 1.9963 \\
\hline 2 & 8.9456 & 8.3864 & 6.341 & 0.3251 & 0.830 & 1.1924 \\
\hline \multirow{3}{*}{$\begin{array}{c}\text { Moisture Content in } \\
\%\end{array}$} & \multicolumn{6}{|c|}{ For Moong } \\
\hline & \multicolumn{3}{|c|}{ Dielectric Constant } & \multicolumn{3}{|c|}{ Loss Factor } \\
\hline & $5.3 \mathrm{GHz}$ & $6.6 \mathrm{GHz}$ & $10.65 \mathrm{GHz}$ & $5.3 \mathrm{GHz}$ & $6.6 \mathrm{GHz}$ & $10.65 \mathrm{GHz}$ \\
\hline 30 & 10.745 & 10.5023 & 7.448 & 1.7532 & 2.041 & 2.3551 \\
\hline 20 & 10.046 & 9.9745 & 6.961 & 1.3577 & 1.976 & 2.2015 \\
\hline 10 & 9.8091 & 9.5967 & 6.345 & 1.1985 & 1.502 & 1.8816 \\
\hline 5 & 9.0552 & 8.8903 & 6.192 & 0.7658 & 0.930 & 1.5891 \\
\hline 2 & 8.9196 & 8.3203 & 5.440 & 0.5194 & 0.529 & 0.6128 \\
\hline
\end{tabular}
moisture meter should be periodically checked to see if it is accurate. One method of checking the meter is to compare it to at least two other meters.

Table 4: Dielectric Constant and loss factor of grains for CJ-Band (5.3 GHz, 6.6 GHz) and X-Band (10.65 GHz)

\section{Volume 6 Issue 9, September 2017




\section{International Journal of Science and Research (IJSR) \\ ISSN (Online): 2319-7064}

Index Copernicus Value (2015): 78.96 | Impact Factor (2015): 6.391

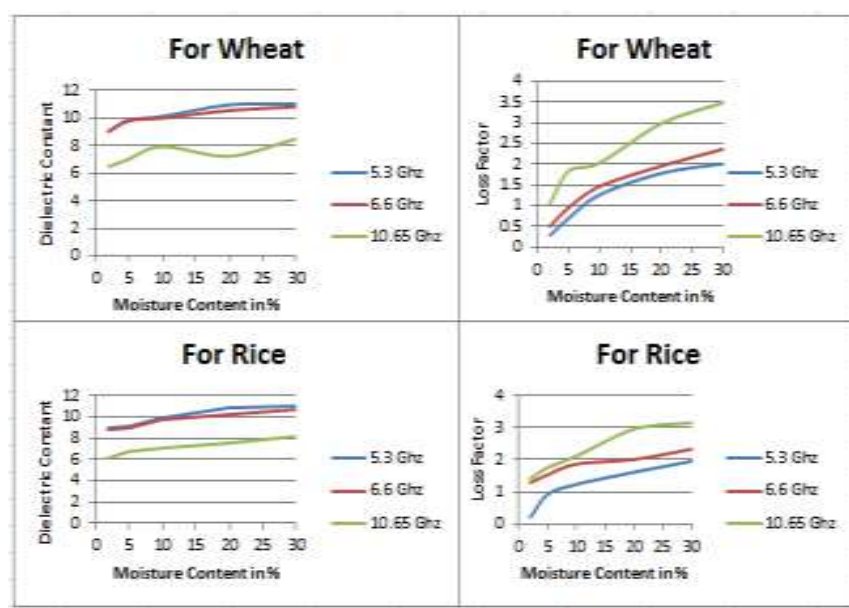

Figure 1: Variation in dielectric constant and Loss Factor for Rice and Wheat samples at different moisture levels

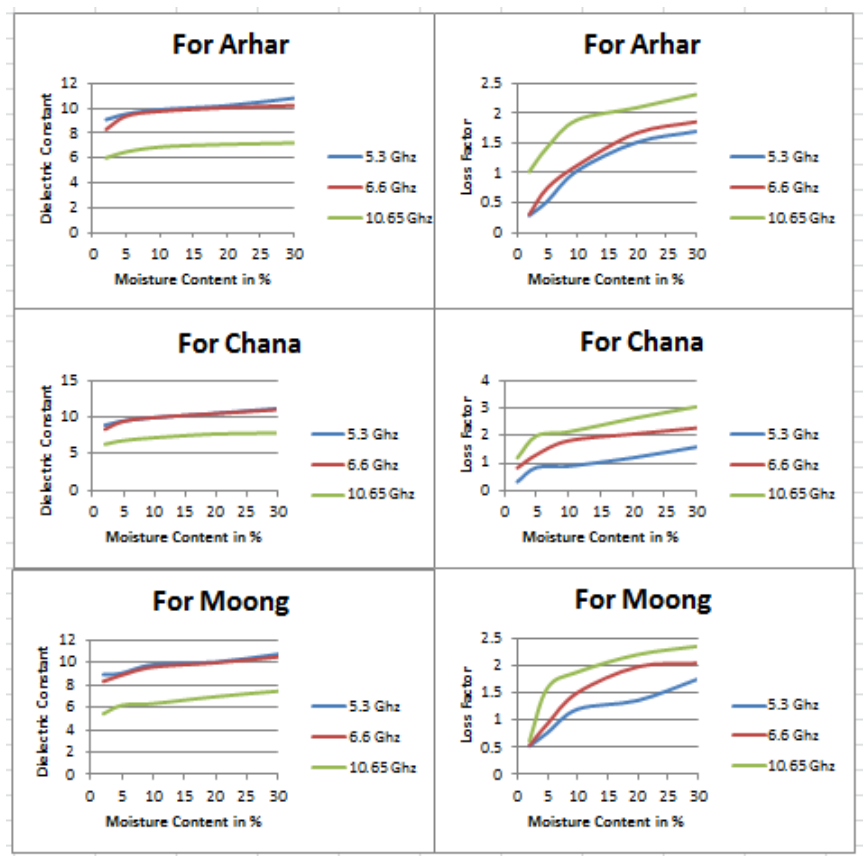

Figure 2: Variation in dielectric constant and Loss Factor for Arhar, Chana and Moong samples at different moisture levels

\section{Conclusion}

In this paper the direction in which the research has moved has been indicated where we estimated the dielectric constant and loss factor of various cereals and pulses using the theoretical models which will compare with the practical values of dielectric constants of same cereals obtained through the radiometer.

This paper also shows the behavior of dielectric constant of cereals and pulses (wheat, rice, Arhar, Chana, Moong) using theoretical model of two point method (double minima wave guide method).

The dielectric constant and loss factor are depend on frequency and stays constant only over relatively small portions of the frequency spectrum .But, the variation of $\varepsilon$ ' with frequency is sufficiently gradual that it can considered to be constant over a fairly wide frequency band for most common microwave applications. The percentage variation in $\varepsilon^{\prime \prime}$ is almost always greater than that of $\varepsilon^{\prime}$, so that $\varepsilon^{\prime \prime}$ should be measured near the frequency or frequencies of interest. In some cases, $\varepsilon^{\prime}$ is affected by temperature, so that the temperature should be held constant. The dielectric constant $\varepsilon^{\prime}$ and loss factor $\varepsilon^{\prime \prime}$ is directly proportional to the moisture content present in the sample.

Through all these tables and figures we observed that the value of dielectric constant $\varepsilon$ ' and loss factor increases with the increase in moisture content. This is due to the presence of free water molecules in the sample. The dielectric constant of water is 80 at around $1 \mathrm{GHz}$ and it decreases with increase in frequency and also the dielectric constant changes when impurities are present in the water. For moisture content, just add distilled water in the samples. The loss factor increases with increase in frequency.

As the research is done over on analog instruments accuracy can be varied around negligible values under minute tolerance limit.

The method for the complex permittivity of cereals has been developed, by maintaining relationships of theoretical and physical significance. The estimated permittivity's and loss factors of rice, wheat, Moong dal, Chana dal, Arhar dal with average accuracies of $5 \%$ to $10 \%$ over the frequency 5.30 , 6.60 and $10.65 \mathrm{GHz}$ and moisture content range from $2 \%$ to $30 \%$, wet basis.

\section{References}

[1] Carol L. Jones, Marvin L. Stone, Niels O. Maness, John B. Solie, Gerald H. Brusewitz, "Plant Biomass Estimation Using Dielectric Properties", Paper Number: 063092, Written for presentation at the 2006 ASABE Annual International Meeting Sponsored by ASABE Portland Convention Center Portland, Oregon

[2] Von Hippel, A. R., "Dielectric Properties and Applications", New York: John Wiley and Sons, 1954.

[3] Nelson, S., "Measurement of microwave dielectric properties of particulate materials", Journal of Food Engineering 21:365-384, 1994.

[4] Trabelsi, S., and S. Nelson, "Free-space measurement of dielectric properties of cereal grain and oilseed at microwave frequencies". Measurement Science and Technology 14:589-600, 2003.

[5] S. O. Nelson, "Electrical properties of agricultural products-A critical review". Transactions of the ASAE, vol. (2)16, pp. 384-400, 1973a.

[6] Nelson, S., "Review of factors influencing the dielectric properties of cereal grains" Cereal Chem .vol. (6)58, pp.487-492, 1981.

[7] Nelson, S., "Observations on the density dependence of the dielectric properties of particulate materials" J. Mircrowave Power vol. (2)18, pp.143-153, 1983.

[8] Nelson, S., "Estimation of permittivities of solids from measurements on pulverized or granular materials", In Dielectric Properties of Heterogeneous Materials. J. A. Kong. New York: Elsevier, 1984.

\section{Volume 6 Issue 9, September 2017




\section{International Journal of Science and Research (IJSR) \\ ISSN (Online): 2319-7064}

Index Copernicus Value (2015): 78.96 Impact Factor (2015): 6.391

[9] Nelson, S., "Dielectric properties of agricultural products", IEEE Transaction on Electrical Insulation vol. (5)26, pp.845-869, 1991.

[10] Nelson, S. and L. Stetson, "Frequency and moisture dependence of the dielectric properties of hard red winter wheat", Journal of Agricultural Engineering Research, vol. (2)21, pp.181-192, 1976.

[11] Manjur Ahmed, FareqMalek, EeMeng Cheng\#, Ahmad NasirCheRosli, Mohammad Shahrazel Razalli, Hasliza A. Rahim, R. Badlishah Ahmad, Rusnida Romli, Mohd Zaizu Ilyas, Muhamad Asmi Romli, "The behaviour of the dielectric properties of paddy seeds with resonance frequencies", International Journal of Electric \& Computer Sciences IJECS-IJENS Vol: 11 No: 01, 2834, 2011

[12] Shaojin Wang And Juming Tang, Radio frequency postharvest quarantine and phytosanitary treatments to control insect pest in fruits and nuts, Production Practices and Quality Assessment of Food Crops, Vol. 4, "Postharvest Treatment and Technology", 2004, pp. 1753.

[13] Andrzej W. Kraszewski, Stuart 0. Nelson and Tian-su You, Use of a Microwave Cavity for Sensing Dielectric Properties of Arbitrarily Shaped Biological Objects, IEEE Transactions on Microwave Theory and techniques, July 1990, Vol. 38, No. 7.

[14] A. Kraszewski, S. 0. Nelson, "Composite Model of the Complex Permittivity of Cereal Grain", J. ugric. Engng Res., vol. 43, 211-219, 1989.

[15] Study of Millimeter Wave Scattering from Ground \& Vegetation at $35 \mathrm{GHz}$, D.R.Godara, S.K.Modi, Rupesh Kumar Rawat, International Journal of Soft Computing and Engineering (IJSCE) ISSN: 2231-2307, Volume-1, Issue-6, January 2012

[16] Trabelsi, S., and S. Nelson. "Free-space measurement of dielectric properties of cereal grain and oilseed at microwave frequencies", Measurement Science and Technology 14:589-600, 2003.

[17] M.S. Venkatesh, G.S.V. Raghavan, "An overview of dielectric properties measuring techniques.-a review", CANADIAN BIOSYSTEMS ENGINEERING, vol. 47, 2005.

[18] Stuart O. Nelson, "Fundamentals of Dielectric Properties Measurements and Agricultural Applications". Journal of Microwave Power and Electromagnetic Energy, vol. 44 (2), pp. 99, 2010.

[19] Stuart O. Nelson, "Sensing grain and seed moisture and density from dielectric properties", Int J Agric \& Biol Eng; vol. 4(1), 2011.

[20] S. O. Nelson, S. Trabelsi, "Models for the microwave dielectric properties of grain and seed", Transactions of the ASABE, vol. 54(2): 549-553, 2011.

[21] O.P.N. Calla, Dinesh Bohra and Rajesh Vyas, "Study of the electrical parameters like dielectric constant, emissivity and scattering coefficient of ice at different physical temperatures at microwave frequencies", International Centre for Radio Science, Proceedings of the URSI General Assembly 2005, New Delhi.

\section{Author Profile}

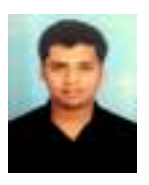

Akhil Kumar Jain received the B.Tech.(Honours) degrees in Akhil Kumar Jain received the B.Tech. (Honours) degrees in Electronics \& Communication Engineering from Institute of Technology Alwar. During his engineering, he worked as researcher in different capacities like RF, Antennas designing, microwave remote sensing and made multiple projects and published research papers. $\mathrm{He}$ is formerly associated with Larsen \& Toubro Infotech ltd and currently associated with Tata Consultancy Services ltd. 